\title{
GAIA Insufficient Evidence for Diagnosis of Gestational Diabetes Mellitus
}

National Cancer Institute

\section{Source}

National Cancer Institute. GAIA Insufficient Evidence for Diagnosis of Gestational

Diabetes Mellitus. NCI Thesaurus. Code C128756.

GAIA Insufficient Evidence for Diagnosis of Gestational Diabetes Mellitus (GDM) is a category of individuals for whom a diagnosis of GDM cannot be made due to one of the following: a) the blood glucose cannot be measured; b) elevated postprandial blood glucose level without confirmatory fasting venous blood or capillary glucose level; c) use of Hemoglobin A1c alone, without a diagnostic oral glucose tolerance test or elevated fasting plasma glucose level; d) clinical and laboratory findings, including glucosuria, fundal height greater than dates, obesity, prior history of GDM, or family history for the diagnosis of gestational diabetes mellitus, without a diagnostic test. 